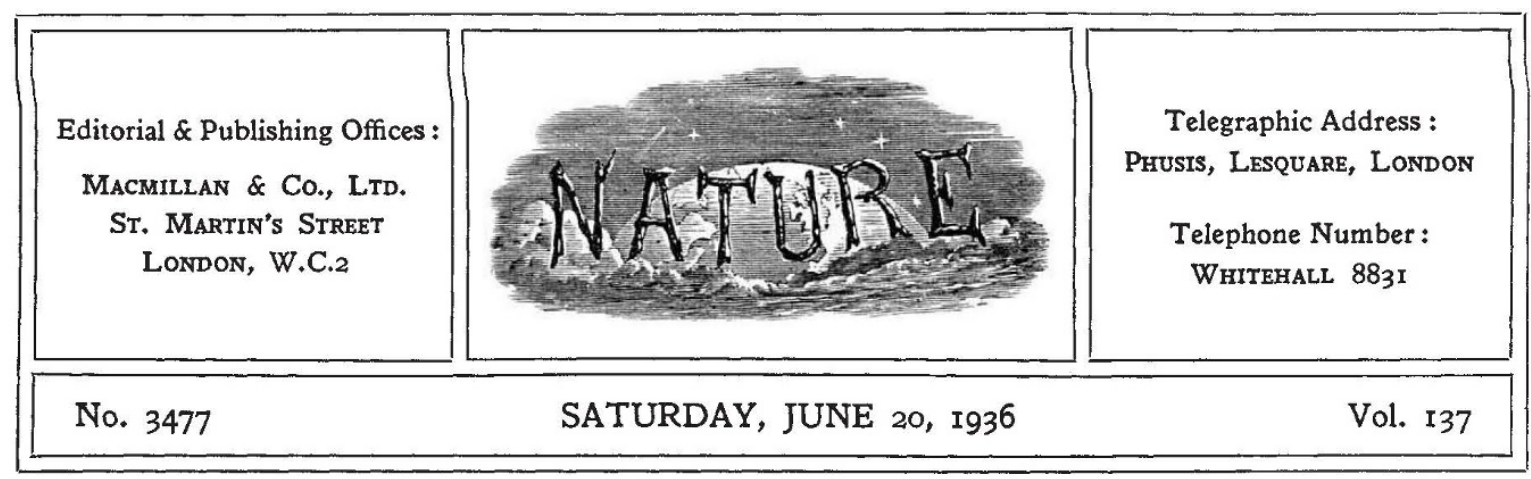

\title{
Training of Industrial Physicists
}

A SHORT time ago, a conference, arranged by the Institute of Physics, was held on the training of industrial physicists. An account of the meeting, by Prof. J. A. Crowther, honorary secretary of the Institute, appears in the May issue of the Journal of Scientific Instruments.

That such a conference should be thought necessary is a striking indication of the increased number of physicists now going into industry. That there should have been, on the industrial side, nearly as many different views as speakers, is, perhaps, evidence of the diversity of subjects with which industrial physicists are now dealing. An employer interested in the crystalline structure of metals quite naturally thinks that his physical staff should have had a different training from those who are going to undertake research in, say, the musical industries. There are, however, a certain number of features in the training, knowledge and the personal qualities of candidates for such industrial posts that most employers of experience will want.

In the first place, the young physicist should have a good honours degree in his subject, with adequate mathematics. It is risky to take a man for a research post immediately after graduation, as a good examinee is not necessarily good at research. About a year's experience in research at a university should give a better idea of his capabilities in this respect than any ordinary examination. $\mathrm{He}$ may even find research less attractive than he thought it would be, and seek to earn his living in other ways. Further, since personal qualities are very important in an industrial position, this research will afford the director of the laboratory a better opportunity to give suitable advice on the choice of a career.
A number of university teachers appear to be strongly in favour of graduates attending the university until the Ph.D. degree is obtained, the argument being that they are being trained in research. In the opinion of scientific industrialists, the time required for this is, from the candidate's point of view, rather wasteful. The earlier he goes into industry the sooner will he become acquainted with the properties of the materials with which he has to work; and if he is fortunate enough to be placed under the supervision of an experienced physicist, there is no reason why his training in research should not take place in the industrial laboratory. If he is going to a laboratory where he will have to rely on his own resources, more post-graduate research will be a great advantage.

An unsatisfactory consequence of spending three years in post-graduate research is that, instead of becoming broader in knowledge, a man is apt to become more and more of a specialist. It is very desirable that the post-graduate training should be designed to widen his range of interests. For example, he might be encouraged to learn some chemistry, and to write essays on some physical problems which would require reference to the original sources in foreign languages. Candidates fresh from the university appear to have had little practice in getting up a new subject without considerable help, and, in general, physicists are not so familiar with foreign languages as are chemists. Some day, it may be hoped, there will be at least one man on the physies staff of universities who will have had experience in commercial research, and may be able to encourage students to look for commercial applications of the knowledge they acquire. 
Little of the very modern theoretical physics finds immediate application in industry, but it is essential that the young physicist should have a good knowledge of the older physics dealing with properties of matter; this is usually a weakness. Again, he may know quite well the properties of thick lens systems, but he often knows little about the actual use of a microscope with high magnification, and he has probably not heard of the conditions for critical illumination; in fact, his knowledge of microscopy usually ends with the use of a measuring microscope. $\mathrm{He}$ is often unacquainted with refractometers, and so neglects a test which is frequently useful. Lack of knowledge of this type is perhaps pardonable when it is remembered that experimental work in a graduate course is designed to elucidate physical principles rather than to obtain a quick result.

A thing that will surprise a scientifically trained man when he enters a works in one of the older industries or one not closely in touch with science, is the number of operations that are carried out without scientific control at each stage. To get this control is one of the present problems of commercial research. Further, it is found in commercial laboratories that a large number of tests are required for which there is no standard testing machine. For both these purposes new testing instruments will have to be devised. The average post-graduate is not very successful at this class of work, probably because his post-graduate reading has been too much concerned with theory. More time should be given to reading the Journal of Scientific Instruments and similar journals, which give many hints on the design of testing apparatus, and the most suitable materials to use in its construction. Coupled with this should go instruction in machine drawing. It is perhaps too much to ask that the student should also attend classes in machine construction and design, but he should certainly do so after taking a post. There is considerable evidence that in the early stages of development of a process, a physicist with a little knowledge of engineering is better than an engineer with little knowledge of physics.

It was rightly remarked at the Conference that the personality of the industrial research worker is as important as his university training; and because of this there are many good physicists who will never reach high administrative positions. The ability to communicate ideas and plans to employers (probably unscientific men) in non. technical language, and, having gained their assent to these schemes, to overcome the inertia and gain the goodwill of the works managers and the workmen, is essential.

The research worker is among the most in. telligent of the employees, and he should be able and willing to go outside physics altogether on occasion. For example, he should be able to suggest selling points to the sales organisation, and even to the advertising staff. Last, but not least, an industrial physicist must be able to apply results of research to commercial use. To be able to visualise practical developments of scientific research is a gift which does not seem to be created by training, but it is one to be cultivated by every physicist who hopes to occupy a leading position in an industrial works.

\section{The Pattern of Culture}

The Fear of the Dead in Primitive Religion By Sir James George Frazer. Vol. 3. Pp. $x+323$. (London : Macmillan and Co., Ltd., 1936.) 10s.6d. net.

$\mathrm{N}^{\circ}$

linguist would think of picking words from a variety of languages none of which he had studied as a whole, and on these pickings base a theory of language. Every linguist knows that structure and function are essential to an under. standing of speech. What is impossible in language is still possible in the study of customs and beliefs.
To take an example. It is a widespread custom to avoid noise, or even to observe complete silence, after a death. Does the anthropologist study thoroughly a few cultures of which this custom is an element in order to determine its relations to other elements? No, he is quite content to collect instances from all over the world, and then to suggest whatever motive his imagination may prompt. In Indonesia his imagination is assisted by the opinion of one whom Sir James Frazer considers "the highest living authority" on that archipelago. That authority thinks complete silence is observed after a death in order "that no 